\title{
Diálogos entre autor e professor: uma leitura da “Arithmetica Elucidativa” de Nelson Benjamim Monção
}

Diologues between the author and the teacher: reading the "Arithmetica Elucidativa” by Nelson Benjamim Monção

Diálogos entre autor y maestro: una lectura de "Arithmetica Elucidativa” de Nelson Benjamim Monção

\author{
BRUNO ALVES DASSIE ${ }^{1}$
}

\section{Resumo}

Atualmente diferentes orientações aos professores sobre o livro didático são elaboradas e publicadas separadamente sob a denominação de manual do professor. No entanto, antes da confecção desse impresso, na década de 1960, é possível encontrar ao longo do livro didático no Brasil orientações destinadas aos docentes. Nessa perspectiva, este artigo tem por objetivo analisar o livro Arithmetica Elucidativa, de Nelson Benjamim Monção, com primeira edição datada em 1923. Consideramos que este livro foi originalmente destinado aos professores, e posteriormente também aos alunos. Mesmo com essa ampliação do destinatário, a leitura dos elementos paratextuais nos leva a um conjunto de orientações de naturezas distintas, utilizadas como estratégias para a constituição de diálogos entre autor e professor.

Palavras-chave: “Arithmetica Elucidativa”; livro didático; manual do professor

${ }^{1}$ Doutor em Educação pela Pontifícia Universidade Católica do Rio de Janeiro. Professor Adjunto da Faculdade de Educação da Universidade Federal Fluminense (Rio de Janeiro). E-mail: badassie@ gmail.com 


\begin{abstract}
Nowadays different guidelines are elaborated and offered to the teachers under the name of teacher's manuals. Nevertheless, in Brazil, in the late 1960s, before the publication of these brochures, we find some guidance to the teacher in the so called textbooks. From this point of view, this paper seeks an analysis on the book Arithmetica Elucidativa, written by Nelson Benjamim Monção. The first edition dates from 1923. This book was originally dedicated to the teachers, but later also to the students. Even if the receiver group was broaden out, reading the paratextual elements shows a range of guidelines of different natures which were used as strategies for the establishment of a dialogue between the author and the teacher.
\end{abstract}

Key-words: Arithmetica Elucidativa, textbooks, teacher's manuals

\title{
Resumen
}

Actualmente diferentes orientaciones acerca del libro didáctico son elaboradas para los maestros y publicadas de modo separado bajo la denominación de manual del maestro. Sin embargo, antes de la confección de este impreso, en la década de 1960, se puede hallar a lo largo del libro didáctico en Brasil orientaciones destinadas a los docentes. En esta perspectiva, este artículo tiene por meta analizar el libro Arithmetica Elucidativa, de Nelson Benjamin Monção. Su primera edición es de 1923. Consideramos que este libro fue en su origen destinado a los profesores y posteriormente también a los alumnos. Aunque haya una ampliación de destinatarios, la lectura de los elementos paratextuales llévanos a un conjunto de orientaciones de distintas naturalezas, que lo vemos como estrategias para la constitución de diálogos entre autor y maestro.

Palabras claves: "Arithmetica Elucidativa". Libro didáctico. Manual del maestro 


\begin{abstract}
Ele [o texto didático] pode buscar preencher diferentes funções em sala de aula: pode se destinar a diferentes leitores; pode buscar construir diferentes formas de mediação entre os alunos e seu professor. Assim, os textos e impressos didáticos podem servir como um instrumento de aprendizado do aluno; podem também buscar organizar o trabalho cotidiano de ensino do professor. Pode ainda servir de complemento ao aprendizado do aluno e ao trabalho do professor, aprofundando temas ou propondo exercícios ou atividades, ensejando utilização tanto individuais como coletivas. (BATISTA, 1999, p. 565)
\end{abstract}

Batista (1999) ao tratar das dificuldades de apreensão e conceituação do livro didático traz ao debate "o modo pelo qual os livros, textos ou impressos didáticos 'encenam' sua leitura e sua utilização, isto é, propõem um 'contrato de leitura' que supõem que seus leitores aceitem” (p. 544). Uma das dimensões discutidas em relação a este "contrato" se refere "ao modo pelo qual seus movimentos de leitura ou de utilização são previstos". Segundo ele, "o professor e os alunos se alternaram, historicamente, como leitores visados pela produção didática" (BATISTA, 1999, p. 550).

A destinação a esse leitor [o aluno] é evidente na organização e na linguagem dos textos e impressos e em sua utilização. [...] No entanto, esse livro dirigido ao aluno deve ser utilizado com a mediação do professor. [...] Os impressos e textos didáticos, desse modo, são tanto um "instrumento de aprendizagem, dirigido prioritariamente ao aluno quanto um instrumento de ensino concebido para ajudar o professor a organizar e preparar suas aulas" (BATISTA, 1999, p. 551, grifos no original).

A constituição de espaços para diálogos entre autores e leitores, em especial os professores, e a diversidade de funções mencionadas por Batista (1999, p. 565) no texto da epígrafe, decorre de um processo complexo que envolve variáveis “[...] de pelo menos três grandes conjuntos de condições: aquelas ligadas a (i) fatores de ordem econômica e tecnológica, (ii) de ordem educacional e pedagógica e (iii) de ordem social e política" (BATISTA, 1999, p. 554). Nesse sentido, Darnton (2010) ao propor um "modelo geral para analisar como os livros surgem e se difundem entre a sociedade" (p. 125) destaca, de maneira latente, a relação entre autores e leitores. Para ele,

[...] de modo geral, os livros impressos passam aproximadamente pelo mesmo ciclo de vida. Este pode ser descrito como um circuito da comunicação que vai do autor ao editor [...], ao impressor, ao distribuidor, ao vendedor, e chega ao leitor. O leitor encerra o circuito porque ele influencia o autor tanto antes quanto depois do ato de composição (DARTON, 2010, p. 125) 
Mas, como pensar nos registros de comunicação entre os autores e professores em livros didáticos, em particular nos livros de matemática?

Atualmente, no Brasil, o Manual do professor, concebido na década de 1960 como volume separado do livro do aluno ${ }^{2}$, é o meio mais explícito de comunicação entre autores e professores na perspectiva de Batista (1999) e Darnton (2010). Com efeito, por influência direta do Programa Nacional do Livro Didático - PNLD, esse manual, destinado ao docente, cumpre diversas funções de formação, como considerado por Gérard e Roegiers (1998): função de informação científica e geral, função de formação pedagógica ligada à disciplina, função de ajuda nas aprendizagens e na gestão das aulas e função de ajuda na avaliação. Para esses autores, o objetivo desse tipo de impresso é contribuir "com instrumentos que permitam aos professores um melhor desempenho do seu papel profissional no processo de ensinoaprendizagem" (GÉRARD; ROEGIERS, 1998, p. 89). Podemos citar também como exemplo as orientações aos autores e editores para a confecção do manual do professor, no Edital PNLD 2015, no item 4.1.8., na seção Das características das obras:

O manual do professor não poderá ser apenas cópia do livro do aluno com os exercícios resolvidos. É necessário que ofereça orientação teórico-metodológica e de articulação dos conteúdos do livro entre si e com outras áreas do conhecimento; ofereça, também, discussão sobre a proposta de avaliação da aprendizagem, leituras e informações adicionais ao livro do aluno, bibliografia, bem como sugestões de leituras que contribuam para a formação e atualização do professor. (BRASIL, 2013, p. 2)

Consequentemente, tais atribuições são concebidas na produção didática por meio de orientações produzidas pelos responsáveis pelo livro e são incorporadas ao longo do livro do aluno e/ou agrupadas em cadernos especiais denominados, em geral, como manual pedagógico. Esses guias contêm, entre outras coisas, apresentação da estrutura do livro e de pressupostos teóricos e metodológicos da coleção; orientações específicas ao professor para o trabalho com os capítulos ou unidades; sugestões de fontes de informação, materiais didáticos e recursos tecnológicos potenciais para o ensino e aprendizagem da Matemática. Além disso, encontram-

\footnotetext{
${ }^{2}$ Em relação às origens desse encarte, Soares (1996) considera que: "Inicialmente, os livros para toda e qualquer disciplina, eram constituídos apenas de textos: cabia ao professor a responsabilidade de decidir como trabalhar didaticamente o texto, e a tarefa de formular exercícios e propor questões; progressivamente, os manuais didáticos passam a incluir exercícios, cada vez mais numerosos, e, a partir de certo momento, passam a ser complementados por um "livro do professor" que explica, orienta, define procedimentos de ensino, e até apresenta as respostas aos exercícios. Ou seja: o autor do livro didático passa a exercer funções até então exclusivas do professor, assumindo, de certa forma a responsabilidade das atividades docentes - o que, aliás, os próprios professores passam a esperar dele. Esse processo ocorre contemporaneamente ao processo de depreciação da função docente: a necessidade de recrutamento mais amplo e, portanto, menos seletivo de professores [...], resultado da democratização do ensino e da multiplicação de alunos dela decorrente, vai conduzindo o rebaixamento salarial e, consequentemente, a precárias condições de trabalho, como também a formação profissional deficiente [...], tudo isso constituindo uma situação que obriga os professores a buscar estratégias de facilitação de sua atividade docente - uma delas é transferir ao livro didático a tarefa de preparar aulas e exercícios (SOARES, 1996, p. 62).
} 
se as respostas de todas as atividades e, em alguns casos, a resolução completa das tarefas propostas, bem como atividades extras.

Em perspectiva histórica, Bittencourt (2008), ao analisar as relações entre livro didático e saber escolar, localiza em produções didáticas de história do século XIX diálogos entre autores e professores constituídos em trechos nas páginas iniciais dos livros. Segundo ela,

O poder do professor na sala de aula, considerando-se que dele dependia a escolha do livro a ser lido pelos alunos e as formas como seria utilizado, obrigou os autores a travar um diálogo com seu interlocutor mais autorizado por intermédio de "introduções", "prefácios" [...], "advertências" que, invariavelmente, iniciavam o livro didático. Tais discursos introdutórios, ao lado do próprio "conteúdo explícito" dos capítulos do livro escolar, indicaram as diferentes concepções dos autores sobre o conhecimento escolar e sobre as metodologias a serem utilizadas no processo de aprendizagem. [...] Os autores acreditavam no papel do livro na constituição do saber escolar por intermédio de um texto impresso, mas estavam cientes do poder da oralidade e da intervenção do professor (BITTENCOURT, 2008, p. 183).

E ainda,

A intervenção dos autores sobre o processo de aprendizagem e uso do livro pelos professores evoluiu para a confecção dos "livros do professor", que eram distribuídos com o livro do aluno, forma de garantir até mesmo que os exercícios escolares fossem realizados corretamente e conforme o pensamento do autor (BITENCOURT, 2008, p. 185).

O livro do professor, citado por Bittencourt (2008), também surge como produto associado aos livros didáticos de Matemática, possivelmente entre o final do século XIX e início do XX. Para Valente (1999), Antônio Trajano foi o primeiro autor a lançar o esse tipo de impresso. Segundo ele, "Trajano [...] parece ter sido o introdutor, no ensino de matemática no Brasil, do livro do professor” (p. 165) com o anúncio na quarta edição de sua Álgebra, em 1901, da Chave da Aritmética Progressiva ${ }^{3}$. Podemos citar também Eulalio (1909a e 1909b), que elaborou as denominadas Postilas de mathematica para sua coleção Curso de mathematica e Dordal (1915), com o Livro dos Mestres associados aos seus cadernos de aritmética 4 .

Também na década de 1910, o "Livro do professor foi introduzido sistematicamente nas coleções da FTD, conforme demonstra o catálogo da Nova coleção de livros clássicos de 1909" (BITTENCOURT, 2008, p. 185). Em geral, esses textos dirigidos ao docente eram denominados Parte do mestre ou, por exemplo, Soluções e Respostas dos Exercícios e

\footnotetext{
${ }^{3}$ No corpo do texto as citações serão feitas na grafia atual, exceto para títulos de impressos.

${ }^{4}$ Costa (2010) cita a quarta edição desta obra, datada em 1903. Uma cópia digitalizada da edição de 1915 deste livro encontra-se disponível em https://repositorio.ufsc.br/xmlui/handle/123456789/126787.
} 
Problemas contidos no livro Elementos de Arithmetica para uso dos alunos do Curso Elementar (F.T.D., s./d.).

Mas, quais as características desse tipo de impresso?

Nos casos citados, tais publicações eram compostas apenas pelas respostas e/ou resolução das questões propostas nos livros-texto. Não havia outras orientações, diretas ou indiretas, para o trabalho com o livro didático e para o trabalho em sala de aula ${ }^{5}$. Qualquer acréscimo se referia diretamente aos exercícios, como, por exemplo, atividades adicionais. É interessante notar que essa publicação complementar, segundo Valente (1999), surge no momento em que "aos poucos a lição vai dando lugar também ao exercício dentro dos textos didáticos de matemática” (p. 173, grifos no original).

À escola liga-se o exercício. Diferente da lição, que era a ordem do saber do mestre posta aos alunos, o exercício é a "autorização que a escola dá ao aluno de mostrar suas dificuldades, seus esforços e seus fracassos. O exercício expõe, antes dos resultados, o momento da aprendizagem"6. Daí compreende-se que o início das discussões didáticas na matemática exija a construção de textos que incluam muitos exercícios para os alunos. (VALENTE, 1999, p. 174)

Assim, alteram-se as práticas de uso do livro por parte do aluno, gerando novos desafios aos professores. Nesse caso, gerenciar as resoluções e as respostas das atividades propostas aos alunos. Essa prática tornou-se comum e, até a década de 1920, encontramos exemplares como os produzidos por Perez y Marin, com a denominação Soluções arithmeticas e Soluções algébricas, contendo "todas as questões da última edição" dos respectivos livros (PEREZ Y MARIN, 1925; 1927).

Por outro lado, ao olhar para a produção didática destinada ao ensino de matemática no ensino secundário, na primeira metade do século XX, antes da produção dos manuais editados separadamente $^{7}$, localizamos diálogos instituídos especificamente para o professor. Obviamente, tais interações não alteram os textos de conteúdo, destinados, a priori, ao aluno devido à constituição dos mesmos, como considerado por Batista (1999, p. 551), citado anteriormente. Observa-se que os espaços utilizados por autores para comunicação com o professor são paratextuais. Na concepção de Genette (2009),

\footnotetext{
${ }^{5}$ Dordal (1915) apresenta no início do livro algumas notas de rodapé para o professor.

${ }^{6}$ HÉBRARD, J. La leçon et l'exercice: quelques réflexions sur l'histoire des pratiques de scolarisation. Paris: INRP-CNRS - Service d'histoire de l'éducation, 1995. Esse texto foi traduzido e publicado no periódico Educação, revista do Centro de Educação da UFSM e encontra-se disponível em http://cascavel.ufsm.br/revistas/ojs-2.2.2/index.php/reveducacao/article/view/657/468. (Acesso em 17 out 2013).

${ }^{7}$ A primeira separata que localizamos, direcionada ao professor, com características distintas dos livros com respostas dos problemas, e associada a uma coleção de livros didáticos, foi o impresso denominado Guia para uso dos professores, de Sangiorgi, publicado na década de 1960, junto com a coleção Matemática, curso moderno. A partir da década de 1960 e de maneira mais intensa no final da década de 1970 e início dos anos 1980, o manual do professor torna-se uma publicação comum. Por exemplo, outro encarte produzido separadamente e que se encontra entre os primeiros a serem editados foi escrito por Trotta, Imenes e Jakubovick para a coleção Matemática aplicada, com seu primeiro volume publicado em 1979.
} 
A obra literária consiste, exaustiva ou essencialmente, num texto, isto é (definição mínima), numa sequência mais ou menos longa de enunciados verbais mais ou menos cheios de significação. Contudo, esse texto raramente se apresenta em estado nu, sem o reforço e o acompanhamento de certo número de produções, verbais ou não, como um nome de autor, um título, um prefácio, ilustrações, que nunca sabemos se devemos ou não considerar parte dele, mas que em todo o caso o cercam e o prolongam, exatamente para apresentá-lo, no sentido habitual do verbo, mas também em seu sentido mais forte: para tornálo presente, para garantir sua presença no mundo, sua "recepção" e seu consumo, sob a forma, pelo menos hoje, de um livro. Esse acompanhamento, de extensão e conduta variáveis, constituiu o que em outro lugar batizei de paratexto da obra [...] Assim, para nós o paratexto é aquilo por meio de que um texto se torna livro e se propõe como tal a seus leitores, e de maneira mais geral ao público (GENETTE, 2009, p. 9, grifos do autor).

Estes elementos encontram-se na capa, nas páginas iniciais, junto ao texto e no final do livro, e são produtos do autor e do editor, as pessoas responsáveis pelos paratextos (GENETTE, 2009).

Nessa perspectiva, interessa-nos, então, investigar como autores orientavam os professores quanto ao uso do livro didático e como o livro didático era utilizado para orientar professores em relação às especificidades da disciplina Matemática ${ }^{8}$. Em particular, neste artigo, nosso objetivo é apresentar uma leitura ${ }^{9}$ do livro Arithmetica Elucidativa de Nelson Benjamim Monção, editado pela primeira vez em 1923.

\section{Arithmetica Elucidativa: um livro para o professor}

Pouca se sabe sobre a trajetória de Nelson Benjamim Monção. Ele nasceu em Januária no Estado de Minas Gerais (ALMEIDA, 2009, p. 77) e depois se mudou para o Rio de Janeiro. Monção formou-se no Curso Normal pela Escola Oficial de Montes Carlos. Em Minas Gerais, atuou como professor em cidades ao norte do estado, ao menos entre 1910 e $1916^{10}$. Além de suas atividades como professor Monção atuou como contador (MONÇÃO, 1933; BRASIL, 1928), sob o título de Doutor em Ciências Comerciais, obtido pela Escola Livre do Estado do Rio de Janeiro (MONÇÃO, 1933). Em 1938, o jornal O Imparcial, relata que Monção estava vias de concluir o curso de bacharel em Direito (AS PUBLICAÇÕES, 1938).

\footnotetext{
${ }^{8}$ Este artigo relaciona-se diretamente com o projeto Paratextos editoriais e livros didáticos de matemática: uma análise de suas funções, financiado FAPERJ, na modalidade Auxílio à Pesquisa - (APQ1 2014/5).

${ }^{9}$ Consideramos aqui as concepções de Garnica e Souza (2012), expressas a seguir: “[...] uma fonte [...] é sempre criada, independentemente de estar disponível ou não, pois é a leitura (e o leitor) que a faz dizer alguma coisa, é o leitor, no ato da leitura, que atribui significado à fonte, que 'faz falar', tornando-a documento" (p. 30).

${ }^{10}$ Esses registros encontram-se no Almanack Laemmert entre os anos 1910 e 1916. Este periódico era publicado anualmente e encontra-se disponível para consulta em http://bndigital.bn.br/acervodigital.
} 
Algumas narrativas de Almeida (2009) contêm informações sobre o contexto mineiro e revelam relações estreitas com a atuação profissional de Monção e, consequentemente, sua produção didática.

[...] Januária mantinha também uma certa liderança cultural e intelectual. O Rio São Francisco e o porto constituíam-se numa referência para o intercâmbio de comunicação com outros centros urbanos e citadinos, como a capital - Belo Horizonte - e com outros Estados. As viagens de vapor ao longo do "Velho Chico" constituíam por si só representações de uma cultura reconhecida como de traquejo e civilidade naqueles sertões.

São de lá, conforme Antônio Emílio Pereira, professores que, em 1896, já eram requisitados em suas escolas particulares na Vila Januária e em Brejo do Amparo, e até pelos estudantes baianos, como mestra Joventina Carneiro, Benedito Casqueiro, Manoel Ambrósio e Nelson Benjamim Monção. Todos eles formaram pessoas e mestres de Bela Lorena e Formoso. Os dois últimos ministravam cursos de formação de professores, dentre seus discípulos, o mestre Benevides Doro. (ALMEIDA, 2009, p. 77)

O senhor Pedro dos Santos mostrou-me também, o livro "Arithmética [sic] Elucidativa" de autoria do professor Nelson Benjamim Monção, com quem estudou o professor Benevides Doro, em Januária; depois o professor Nelson se tornou um editor em São Paulo e sempre enviava exemplares dos seus livros a ex-aluno e amigo.

O livro "Arithmética [sic] Elucidativa: o livro do povo"11" acima mencionado pelo meu entrevistado, traz em sua capa o enunciado da sua abordagem: "Ensino Prático e Intuitivo". Demonstra a disseminação do método pelos professores da região, inclusive com uma produção regional nessa direção. (ALMEIDA, 2009, p.263-264)

O livro citado, Arithmetica Elucidativa, foi uma publicação independente. A comercialização deste livro foi feita pela Livraria Francisco Alves e diretamente com o autor em sua residência, então no bairro de Piedade, no Rio de Janeiro, como registrado na folha de rosto da terceira edição de 1928. Relata-se que Monção viajava ao longo do Brasil para apresentar e divulgar o livro (AS PUBLICAÇÕES, 1938). A primeira edição foi publicada em 1923, como consta no prefácio ${ }^{12}$.

Alguns registros no livro apontam para o fato de que, a priori, este impresso foi elaborado para professores. Em especial, destacam-se os denominados Pareceres, anexados à

\footnotetext{
${ }^{11} \mathrm{Na}$ oitava edição, na folha de rosto, há uma lista de obras publicadas por Monção, onde este livro, Arithmetica Elucidativa, é apresentado com subtítulos complementares: O livro das escolas modernas e O livro do povo, este último como referência à oitava edição.

12 Neste artigo utilizamos a terceira edição, de 1928, e oitava, de 1933. Nessas edições, encontra-se também, com a denominação de Appendice, a segunda edição do livro Noções de escripturação mercantil por partidas dobradas, do mesmo autor. Segundo consta na folha de rosto, este impresso foi adotado em "vários colégios e escolas de comercio do Distrito Federal e dos Estados de Minas Gerais, Espírito Santo e outros do Brasil" e destinava-se ao "uso dos comerciantes, empregados de escritórios, dos alunos dos cursos primários e complementares e da mocidade estudiosa". Essa parte não será analisada.
} 
obra e elaborados por leitores críticos da primeira edição. O conjunto desses textos é composto por cartas cujos signatários mantinham relações com a escola (como diretores, professores e inspetores), cartas de amigos e resenhas publicadas na imprensa periódica ${ }^{13}$.

É possível observar explicitamente a intenção de Monção na determinação do público alvo. José de Carvalho Filho, de Araguari, se refere elogiosamente ao manuscrito da "obra didática, aritmética para uso do professorado primário". Victor Coelho de Almeida, do Rio de Janeiro, finaliza seu parecer afirmando que o livro de Monção é um manual para professores e que o mesmo "ensina, ainda, a ensinar Aritmética aos alunos". O texto de Luiza Soares Mattos, do então distrito de Córregos, no munício de Conceição do Serro, é também um exemplo significativo sobre a proposta de um impresso didático destinado ao professor.

Córregos, mº de Conceição do Serro, 26 de setembro de 1923.

Ilmo. Sr. Prof. Monção.

Distinto colega.

Saudações.

Com prazer proclamo a excelência de sua Arithmetica Elucidativa, que é realmente um "Manual do Professor", pois contém lições tão claras e ensinamentos tão úteis, que serve de guia a qualquer professor, tanto aos competentes, como àqueles que lutam com dificuldades nesta melindrosa carreira.

Com grande satisfação, tenho notado que alguns de meus discípulos, que detestavam essa matéria, muito têm aproveitado nestes últimos meses, depois que comecei a lecioná-los, guiando-me pelo seu livro. Qual não foi a minha surpresa e contentamento, quando dois de meus alunos, que sentiam grande aversão ao estudo da Aritmética, declararam-me que agora estudam com gosto e desejariam até, se possível fosse, uma aula de Aritmética todos os dias! É que o seu livro contém todo o programa primário, não havendo nele regras decorativas e enfadonhas, mas sim uma exposição em linguagem clara, capaz de atrair o aluno por mais refratário que seja ao estudo dessa disciplina.

Portanto, ilustre colega, queira aceitar os meus parabéns, desejando que o seu livro tenha mesmo muita aceitação, porque assim muito irá auxiliar ao professorado primário.

Da colega e admra.

Luiza Soares de Mattos (apud MONÇÃO, 1928, p. 22)

Outro texto que merece destaque é o de Antonio Navarro, não apenas pelo fato de o próprio Monção apontar este como exemplo dos "pareceres de pessoas ilustres e autorizadas no assunto", mas também pelas preocupações com a produção de livros didáticos e suas relações com o professor, já no início do século XX no Brasil ${ }^{14}$.

13 Pelos registros, pode-se considerar que este livro, ao menos em sua versão preliminar, foi fruto das experiências de Monção como professor no Estado de Minas Gerais. As indicações localizadas de sua atuação, como já citado neste texto, datam entre 1910 e 1916 e as cartas iniciais entre 1917 e 1918 . Observa-se, também, devido às datas das quatro primeiras cartas, que este impresso possuiu uma versão preliminar.

${ }^{14}$ Antonio Navarro foi um dos organizadores do $2^{\circ}$ Congresso Brasileiro de Instrução Primária e Secundária, realizado em Belo Horizonte, em 1912. 
Belo Horizonte, 25 de fevereiro de 1918.

Meu caro amigo Nelson Monção.

V. [sic] está fazendo o que os Franceses já usam há muito tempo a respeito de livros didáticos, e o que, no Congresso de Educação e Ensino, reunido em Belo Horizonte, em 1912, em Memória lida perante esse Congresso, eu pedi que se fizesse com relação ao ensino da língua portuguesa - livros para professores. São muitos os "Livres du Maitre" dos Franceses, ao lado dos "Livres de L'Élève". As muitas obras de F.I.C. acerca das matemáticas são escritas sob esse dualismo ${ }^{15}$. Ora, é o quanto basta para justificar essa sua boa ideia de escrever a Arithmetica Elucidativa como guia para os professores, mesmo para aqueles que são profundos conhecedores da matéria, porque um professor pode demonstrar com proficiência os teoremas de Euler, de Fermat e de Wilson, e não ser capaz de ensinar as crianças os rudimentos da aritmética, nem saber como um tal curso se fará. (apud MONÇÃO, 1928, p. 17, grifos no original)

Os registros destacados apontam, como já citado, para o fato de que o livro de Monção foi originalmente constituído para professores. Tais paratextos se referem à primeira edição do livro, como pode ser visto na disposição dos textos na terceira e oitava edições.

Apesar de Monção ampliar o seu público-alvo ${ }^{16}$, no Prologo da segunda edição ele continua reiterando a especificidade do professor como seu principal destinatário. Para Monção, o livro é um "compêndio de prática profissional", pois o contém "um método moderno, claro, intuitivo, pratico, racional" além de "todas as lições do curso primário, numa linguagem interessante e atraente do professor falando aos alunos" (MONÇÃO, 1928, p. 12). Cabe destacar, também, que Monção, neste mesmo prefácio, denomina os aditivos que são direcionados aos professores como notas pedagógicas. (MONÇÃO, 1928, p. 12). Estas características o diferem das demais publicações didáticas de aritmética que circulavam no Brasil.

Costa (2010), objetivando analisar o percurso da aritmética na escola primária no Brasil considera em sua pesquisa os livros didáticos como fonte singular e nos apresenta uma ampla lista de livros publicados para este fim, entre o século XIX e XX. Em particular, pode-se estabelecer a partir deste trabalho um elenco de obras de aritmética cujas edições circularam no Brasil nas primeiras décadas do século XX, período em que o livro de Monção foi publicado e reeditado. Nessa lista, encontram-se os autores Ramon Roca Dordal, Arthur Thiré, René Barreto, G.A. Bücher, Benedicto M. Tolosa, Irmão Isidoro Dumont, Antonio Trajano, Hipérides Zanello e Lourenço Filho. A partir do contexto paulista, Costa (2010) relaciona o mercado editorial, no qual também se insere Monção, com as alterações da escola, com

(http://www.histedbr.fe.unicamp.br/navegando/referencias_documentais/Alessandro\%20Cesar\%20Bigheto\% 20-\%20ref_doc.htm). Navarro também foi autor de um livro de aritmética, denominado Elementos de arithmetica: curso superior, publicado em 1918, em Belo Horizonte, impresso na Imprensa Official do Estado de Minas.

${ }^{15}$ Os livros didáticos de matemática da coleção F.I.C., no Brasil, foram traduzidos por Eugênio de Barros Raja Gabaglia, mas não encontramos referência sobre as traduções dos livros do mestre.

${ }^{16}$ Observa-se, a partir do prefácio da segunda edição, que os alunos tornam-se também destinatários declarados de Monção. 
destaque para a criação dos Grupos Escolares e das Escolas Normais (COSTA, 2010, p.182185), justamente os setores de atuação profissional visados por Monção.

A partir da leitura dessas obras é possível observar que o texto foi constituído centrado nos conteúdos, prática comum nesse tipo de impresso destinado aos ramos da matemática escolar. Em sua análise específica do conceito de número, Costa (2010) apresenta diversos trechos dos autores citados anteriormente que podem ser tomados como exemplos dessa natureza. Observa-se que não há o uso de estratégias de diálogos com o leitor professor, mas veem-se textos cujo objetivo é a apresentação dos conceitos de maneira sistematizada como um livro de referência, por mais cuidadosa que seja essa confecção devido o nível priorizado.

Em alguns casos, têm-se orientações aos professores. Mas, essas diretrizes foram produzidas em forma de lista separada do texto de conteúdo, como é o caso de Benedicto $\mathrm{M}$. Tolosa e suas Direcções geraes para o uso do Caderno de Problemas Arithmeticos do $2^{\circ}$ anno primário (COSTA, 2010, p.237-238).

Considera-se, portanto que a aritmética de Monção destaca-se pela amplitude e diversidade de orientações destinadas aos professores. Essas instruções podem ser classificadas de acordo com a natureza de seus diálogos, como indicado na interpretação que segue.

\section{A natureza dos diálogos: uma estrutura de manual para professores}

As edições utilizadas neste artigo contêm uma série de elementos paratextuais que se relacionam diretamente com o professor. É possível, portanto, identificar no livro, diálogos de diversas naturezas, interpretando a aritmética de Monção como uma obra cuja estrutura é a de um manual para professores. O texto de aritmética é cercado de elementos pretextais (folha de rosto; dedicatórias; prefácios da primeira e segunda edições e da edição corrente; instruções oficiais; pareceres sobre a primeira edição e edições subsequentes) e elementos pós textuais (índice geral da obra; índices especiais relacionados a diversos programas de ensino; e errata). Por questões de organização esta parte do artigo está separada em três, sendo a primeira correspondente aos elementos pré e pós textuais, a segunda ao texto de conteúdo, e a terceira às notas de rodapé.

\section{Diálogos nos elementos pré e pós-textuais}

O prefácio da primeira edição do livro de Monção acumula funções interessantes. A partir dos aspectos mencionados por Genette (2009) articulam-se nesse prefácio as funções de orientar o leitor, situando-o quanto "a origem da obra, sobre as circunstâncias de sua redação, sobre as etapas de sua gênese”. (GENETTE, 2009, p.187 e 189). Para tal fim, Monção inicia esse prefácio atribuindo o subtítulo Manual dos Professores ao seu livro e assumindo tal produção como "a mais completa e a única escrita de inteiro acordo com o programa oficial" para uso dos docentes dos grupos escolares e das escolas singulares (MONÇÃO, 1928, p. 9). Monção se refere aos professores do Estado de Minas Gerais. Para a primeira edição, os parâmetros oficiais utilizados por ele foram os programas de ensino dos grupos escolares, publicado pelo Decreto n. 4930, de 6 de fevereiro de 1918.

Estes programas foram organizados por semestre e distribuídos em quatro anos. Diferentemente de programas de ensino do curso secundário do mesmo período, por exemplo, 
os do Colégio Pedro $\mathrm{II}^{17}$, a organização dos programas de aritmética para cada semestre não se reduz a uma lista de conteúdos ou conceitos a serem tratados. Há também, como registrado, orientações associadas aos tópicos. A seguir um extrato do primeiro semestre do primeiro ano para exemplificar.

Ideia dos valores um, dois, três, etc., até nove, contanto coisas, os móveis, os alunos, objetos da sala e outros diferentes e bem variados, separando-os pelas qualidades, tamanhos, cores, etc., comparando-os pela quantidade, bem como exercitando-os na taboa de Packer e no Contato mecânico, ou em figuras no quadro negro até que o aluno distinga com precisão o que é mais e o que é menos e saiba qual o número imediatamente superior e o inferior, na ordem natural da numeração (COLLECÇÃO, 1918, p. 57).

Observa-se que tais indicações contribuem para o trabalho dos professores em suas práticas e, neste caso, são referências para Monção na produção do seu texto de aritmética.

Os prefácios da segunda e terceira edições apresentam uma ampliação em relação aos programas de ensino considerados como base para a confecção do livro. Segundo Monção, a segunda edição,

[...] foi moldada aos programas de ensino de vários Estados do Brasil, e por isso, contém, além de todos os pontos, sem exclusão de um só, dos programas que baixaram com o Decreto n. 6758, de $1^{\circ}$ de janeiro de 1925, muitos outros ainda, pelo que a matéria nela estudada constitui o "Curso primário e complementar" (MONÇÃO, 1928, p. 11-12)

O decreto citado por ele aprova os programas de ensino do ensino primário do Estado de Minas Gerais (COLLECÇÃO, 1926).

Este decreto é para Monção um eixo norteador de suas propostas, na segunda edição como declarado, e nas edições seguintes. Com efeito, as "instruções oficiais, observadas, tanto quanto possível, na organização" da segunda edição, permaneceram transcritas nas terceira e oitava edições. Essas orientações, além de refletir os pressupostos adotados por Monção indicam também ao professor ações a serem seguidas em suas práticas. Dessa maneira, a presença deste texto nos elementos pré-textuais do livro são fontes de informações relacionadas ao ensino de aritmética na perspectiva metodológica. Vejamos um extrato:

\section{$[\ldots]$}

III. Todos os problemas, dados como exercícios, devem referir-se a assuntos da vida prática, evitando-se questões meramente teóricas e inutilmente complicadas. Deve-se habituar o aluno a analisar os elementos do problema, antes de resolvê-lo, e a dispor metodicamente os cálculos.

\footnotetext{
${ }^{17}$ Ver, por exemplo, Beltrame (2000).
} 
IV. Não se deve passar às operações seguintes, enquanto a anterior não estiver completamente aprendida.

[...]

XI. Se o ensino de aritmética for realizado com muitos e variados exercícios práticos, pequenos e bem metodizados, apresentará forçosamente, frutos apreciáveis. A sua eficiência depende da orientação inteligente que lhe imprimir o professor, a qual consistirá na concretização constante das noções a transmitir. (MONÇÃO, 1933, p.15-16).

Nos prefácios da terceira e oitava edições as referências estaduais em relação aos programas de ensino mencionadas anteriormente são agora explicitadas. Segundo Monção, essas edições foram moldadas segundo os

[...] programas oficiais [...] primários e complementares, do Distrito Federal, dos Estados do Rio de Janeiro, Minas Gerais, Goiás, Espírito Santo, São Paulo, Santa Catarina e Rio Grande do Sul, programas esses que abrangem os demais Estados do Brasil (MONÇÃO, 1928, p.33; MONÇÃO, 1933, p.37).

Relacionado a este fato, Monção constituiu para o professor um índice do livro a partir os programas de ensino do Distrito Federal e dos Estados do Rio de Janeiro e Minas Gerais. Este índice, alocado ao final da obra, associa cada item dos respectivos programas às páginas do seu livro ${ }^{18}$. O trecho do programa do Distrito Federal a seguir ilustra essa estratégia:

\section{Primeiro ano}

- Coleção - Unidade. Numeração até dez. Algarismos - Zero - Dezena, [p.] 44-48; Nota, pag. 82.

- As quatro operações fundamentais dentro da dezena, [p.] 65; 70; 131; 161-162 ( $1^{\circ}$ e $2^{\circ}$ probs.).

- Metade e quarta parte dos números até dez, [p.] 76 - Duplo e quádruplo, [p.] 75.

- Mapa de Parker - Cálculo mental, [p.] 48-49; 82-84.

- Numeração até 100. Centena, [p.] 49-58.

- As três primeiras operações dentro da centena, [p.] 63-64; 66-68; 7172; 79-81; 130-133.

- Metade e quarta parte dos números até cem, [p.] 76.

- Leitura das horas do relógio (inteiras, meias, quartos) - Sinais romanos no relógio, [p.] 140-142; 125. (MONÇÃO, 1928, p.XII).

\footnotetext{
${ }^{18}$ Esse índice não está presente na oitava edição.
} 
Apesar deste tipo de associação já ser um recurso já visto em outros livros didáticos, e que relaciona o mercado editorial e os programas oficiais ${ }^{19}$, este paralelo é um elemento importante para o professor quanto à adequação da obra em cumprimento aos programas de ensino locais e as especificidades de adoção do livro.

Assim, seleção e distribuição de conteúdos e questões teórico-metodológicas são as características principais destas orientações.

\section{Diálogos junto ao texto de conteúdo}

O texto da aritmética de Monção está dividido em quatro unidades denominadas de livro. Cada uma dessas unidades é dividida em duas partes, que por sua vez subdividem-se em capítulos. Assim, a obra de Monção é composta por quarenta e oito capítulos. Todos os livros possuem a mesma estrutura de organização. Ao longo da obra há diversos blocos com exercícios propostos. Imagens e tabelas são apresentadas e relacionadas com os temas desenvolvidos ao longo das unidades.

Os sumários de cada uma das partes iniciam o diálogo com o professor não apenas por anunciar o que será tratado nos capítulos, mas também por apresentar orientações metodológicas. Vejamos um trecho do sumário da parte segunda do livro primeiro:

I Formação da taboa de subtração, empregando o respectivo sinal e meios intuitivos - II. Ideia de dúzia, de cento, de milheiro, de décimo, de quinto, de oitavo, com muitos exercícios práticos e interessantes. - III. Exercícios dos números com as medidas métricas mais comuns, moedas de prata, de níquel e de cobre. Divisão do tempo. - IV. Leitura e escrita das diversas ordens de unidades completas e com excesso de unidades até um milhão. - V. Operações de soma e subtração em problemas concretos, orais e depois escritos. - IV. Problemas variados com quaisquer números sobre adição e subtração. (MONÇÃO, 1928, p.79)

Observa-se que a maneira como Monção redigiu os sumários se assemelha à apresentação dos programas de ensino de 1918, que ele toma por base para a produção do texto, e já citados anteriormente. Em seguida, os trechos correspondentes a cada capítulo são reapresentados no início de cada um deles, sendo essa uma estratégia de construção de um sumário das partes e ao mesmo tempo de uma introdução para cada capítulo.

As táticas de confecção de um texto para o professor se estendem ao longo das lições.

Cada capítulo é subdivido em lições e o número dessas é variável ao longo das partes. A ementa constituída por Monção, contida no sumário, é complementada com o anuncio do número de lições que compõe o capítulo. Tomando como exemplo, o quinto capítulo, da primeira parte do Livro terceiro, que trata das frações ordinárias e as operações com as mesmas, tem-se um capítulo dividido em quinze lições ${ }^{20}$.

\footnotetext{
${ }^{19}$ Por exemplo, nas páginas iniciais de Perez y Marin (1918) há uma seção denominada Programa do Collegio Pedro II com uma correspondência entre o livro e o programa de ensino (pp. 3-8).

${ }^{20}$ As lições possuem estruturas diferenciadas. Em geral, as primeiras lições de cada capítulo apresentam texto de conteúdo com ou sem propostas de exercícios. Algumas lições são compostas apenas por exercícios.
} 
Além dos sumários e os complementos, há outras orientações de Monção presentes no texto de conteúdo. Algumas instruções são estabelecidas a partir de interlocuções que simulam um discurso envolvendo a figura do aluno, mas em um processo enunciativo de ações do professor. Monção constrói este tipo de diálogo em diversas situações, dentre elas, na explicação de conceitos associada com propostas de exercícios, na apresentação de procedimentos e de definições articulada com exemplos e, por fim, no anúncio de conteúdos. Os trechos a seguir podem ser destacados como exemplos:

Os senhores alunos já sabem efetuar a multiplicação de um número qualquer por um número simples. Passemos agora à multiplicação de dois números quaisquer. (MONÇÃO, 1928, p. 157)

A lição de hoje, caros alunos, versa sobre equivalência de diversas medidas antigas com as medidas correspondentes do sistema métrico. Façamos a lição no "quadro negro". (MONÇÃO, 1928, p. 272)

O assunto de que vamos ocupar hoje, jovens alunos, é a medição cúbica, que tem por fim achar o tamanho ou volume dos corpos e também a capacidade de uma sala, etc. (MONÇÃO, 1928, p. 275)

Fatura é uma relação circunstanciada mencionando o número, a marca, o peso dos volumes enviados, o conteúdo, os preços, as despesas e mais declarações. Vou dar aos senhores alunos o modelo de uma, que passarão para os cadernos mensais, afim de fazerem várias outras. (MONÇÃO, 1928, p. 289)

Outra estratégia adotada por Monção, na mesma perspectiva, encontra-se em trechos denominados de conversação. Vejamos um desses textos, que leva em consideração o calendário escolar, referente ao período de recesso:

Jovens alunos!

Depois de nos termos ausentado desta casa durante o período das férias, eis-nos aqui, de novo, para recomeçarmos os nossos trabalhos. É possível que, nesse período de ausência, os meus caros amiguinhos se tenham esquecido um pouco das matérias estudadas. Tratando-se do estudo da aritmética, sejam, pois, as nossas primeiras lições uma recapitulação geral das operações de soma e subtração. Antes, porém, jovens alunos, de terminar esta breve conversação, quero prevalecerme da oportunidade para lhes dar algumas explicações úteis sobre a matéria de que ora nos ocupamos, o que ainda não fiz, porque só de agora em diante os senhores poderão compreender bem. [...] Concluindo esta palestra instrutiva, tenho a dizer-lhes, jovens alunos, que os conhecimentos que já adquiriram, nas lições estudadas, constituem o alicerce sólido sobre o qual repousa o edifício da Arithmetica Elucidativa, a qual lhe servirá de farol nas escabrosidades da vida prática. (MONÇÃO, 1928, p. 121-122) 
Ao longo das lições há ainda indicações de ações relacionadas com a organização do professor para a apresentação de conceitos. Por exemplo, na página 48, ao tratar de ordens do sistema de numeração decimal, Monção intercala o texto com um quadro, que associa posição à ordem, e aponta que este esquema é um exemplo para o "quadro negro". Tanto o texto que precede quanto o que se encontra após o esboço está relacionado a esta reprodução por parte do professor. O mesmo ocorre, por exemplo, com tabelas de subtração (MONÇÃO, 1928, p. 81).

Os exercícios também são, em sua maioria, orientados e há uma tipologia diversa, com sentidos próprios. Os exercícios denominados escritos estão alocados sempre após textos indicativos do tipo: "Já sabendo ler bem os números que exprimem unidades e dezenas, vamos hoje, caros alunos, aprender a escrevê-los. Copiem em suas lousas os números que vou escrever no 'quadro negro'”. (MONÇÃO, 1928, p. 51). As lições compostas apenas por exercícios são precedidas de uma ementa que os caracteriza. Por exemplo, na $55^{\text {a }}$ lição da primeira parte do segundo livro, encontram-se os "exercícios mentais, muito simples, das duas primeiras operações, a princípio, e, em seguida, das três, combinadamente" (MONÇÃO, 1928, p. 135). Além desses tipos, Monção também nomeia alguns blocos de exercícios orais, cuja denominação já orienta o professor.

Cabe destacar que todas as atividades propostas estão acompanhadas das respectivas respostas, tornando desnecessária uma publicação separada do livro que contemplasse esse aspecto. Esse conjunto de orientações elaboradas por Monção ao longo do texto se assemelha, portanto, a glosas, marginais ou interlineares.

\section{Diálogos nas notas de rodapé}

Monção também constituiu um sistema de diálogo com o professor que se diferencia materialmente do texto de conteúdo pela localização no rodapé ${ }^{21}$. O sistema de notas utilizado por ele corrobora com a concepção de Araújo (2008) e é composto de "acréscimo ou aditamento ao texto" (ARAÚJO, 2008, p. 97). Observa-se, nos originais, que, nesse sistema, foi considerada "a articulação entre as necessidades intrínsecas do texto, com os seus aditamentos, e a programação gráfica com que esse conjunto (texto e notas) se apresentou ao leitor" (ARAÚJO, 2008, p. 98).

Monção produz cerca de cem notas de rodapé. Percebe-se que o professor é considerado o seu principal destinatário. Como apontado por Genette (2009),

[...] mais ainda do que o prefácio, as notas podem ser, em termo de estatuto, de leitura facultativa e endereçar-se, por conseguinte, apenas a alguns leitores: aqueles a quem possa interessar determinada consideração complementar ou digressiva, cujo caráter acessório justifica exatamente a colocação em nota. (GENETTE, 2009, p. 285)

\footnotetext{
${ }^{21}$ Os textos de Gomes (2008) e Dassie e Baptista (2014) são exemplos de analises de notas de rodapé em livros didáticos.
} 
As notas podem ser agrupadas a partir de nossa leitura, como segue.

Cerca de metade das notas de rodapé são notas sobre os conteúdos e se caracterizam como informações complementares a um determinado tópico. São apresentadas acepções de termos específicos ou associados aos conceitos, definições, explicações sobre notação, descrições sobre procedimentos e notas com informações básicas. Os exemplos a seguir ilustram tais aspectos:

Definições. Número é o resultado da comparação de uma quantidade conhecida, tomada como unidade, com outra quantidade desconhecida. Comparando o metro (unidade) com o comprimento do "quadro negro" (quantidade desconhecida), por exemplo, achamos que este contém aquele 4 vezes: 4 , resultado da comparação, é, pois, um número. E como este número consta de um só algarismo, chama-se número simples. Um número que consta de mais de um algarismo, como 10, 15, 4205, etc., chama-se número composto. (MONÇÃO, 1928, p. 147)

Quando, praticando o primeiro processo exposto, chegarmos a uma linha cujos números sejam primos ou primos entre si, não é mister prosseguirmos até que os quocientes se tornem 1; basta multiplicarmos o produto continuado até que achados pelo produto continuado dos números primos ou primos entre si, da referida linha, como acontece nos exemplos indicados pelo asteriscos [...] (MONÇÃO, 1928, p. 213)

Observa-se que os textos não citam explicitamente ao professor, mas a articulação entre as notas e os conteúdos que são desenvolvidos, e aditivados por elas, são orientações formativas para o docente.

Associadas também a conceitos, cerca de um quarto das notas, apresentam indicações com orientações didáticas para o uso do livro e suas relações com as práticas de sala de aula. Por exemplo:

Pelas explicações dadas, os alunos poderão fazer novas tábuas de soma, convertendo-as, em seguida, em tábuas de subtrair. É um exercício útil, necessário e agradável, que se faz com um dos alunos no "quadro negro" à vista da classe. Quando cada aluno estiver bem exercitado, fálo-ão todos em suas lousas. (MONÇÃO, 1928, p. 81)

O professor procurará elucidar este ponto, com os últimos anos bissextos, subtraindo ou adicionando 4 , ao bissexto proposto, pois que os alunos ainda desconhecem a operação de divisão. Exs.: tendo 1916 sido bissexto, o foram 1916 - 4 ou 1912, 1908, etc., e sê-lo-ão 1916 + 4 ou 1920, 1924, 1928, etc. (MONÇÃO, 1928, p. 91) 
Estas são notas que apresentam as interlocuções diretas entre autor e o professor. Seu conteúdo expõe orientação explícita à condução que se deve manter para o ensino de determinado conceito.

Em outros momentos, encontram-se orientações de mesma natureza que se apresentam com uma linguagem ainda mais imperativa, contribuindo assim para um modelo de impresso responsável por "substituir" as individualidades de cada professor, por apresentar métodos supostamente comprovados. Vejamos:

O professor fará, no "quadro negro", como no exercício acima, traços, figuras de sementes, frutas, etc., e os números que os representam. À vista da classe, fará contagem de objetos, tais como: lápis, canetas, sementes, livros, esferas do contador mecânico, etc. Depois fazendo cada aluno contar esses objetos, mandá-lo-á apontar, no exercício feito no quadro, os números que os representam. (MONÇÃO, 1928, p. 45)

Toda vez que houver oportunidade do uso da lousa, o professor chamará um dos alunos ao quadro negro, para dissertar sobre a lição. Todos, a revezes, irão, assim, adquirindo o hábito do manejo do giz, o que é indispensável. (MONÇÃO, 1928, p. 67)

O professor mandará os alunos fazer, nas lousas e no "quadro negro", tábuas de somar de 1 até 9, e depois, de 10 em diante, segundo a explicação dada para formação das tábuas. $\mathrm{O}$ estudo das tábuas que deve ser feito pelos alunos, em suas casas, é necessário; porém, isto só depois que eles estiverem familiarizados com os números, e já tiverem uma certa soma de conhecimentos, não só da numeração, como dos cálculos. Assim, o exigem os programas feitos, a nosso ver, de inteiro acordo com a moderna Pedagogia, e, por isso mandam [que] sejam observadas as mais rudimentares noções de Metodologia (parte da Pedagogia). (MONÇÃO, 1928, p. 64)

À proporção que esta lição for sendo ministrada, os alunos devem ir tomando nota, nos seus cadernos mensais, dos números das medidas correspondentes, para os decorarem bem. (MONÇÃO, 1928, p. 273)

É interessante observar que essas notas também expõem o uso de utensílios, na perspectiva da "cultura material escolar", com o "emprego das lousas e do quadro-negro nas práticas escolares” (BARRA, 2013, p. 129). Sobre esse aspecto, Bastos (2005) aponta: 
Viñao Frago e Escolano Benito (1998, p. 121) ${ }^{22}$ destacam o papel da sala de aula ou as relações entre os métodos pedagógicos e a disposição espacial e dos objetos. Assinalam que são os conteúdos pedagógicos que dão qualidade ao espaço. Nessa perspectiva, o mobiliário escolar refletiria a pedagogia, na qual o quadro-negro ocupa especial centralidade. Pode-se afirmar que a centralidade pedagógica do e no quadro-negro resulta da ausência de manuais escolares e de outros recursos visuais para a aprendizagem. Também a centralidade do processo pedagógico na figura do professor e o seu distanciamento, localizado sob um estrado, exige o quadro-negro, os quadros murais, as lousas dos alunos. (BASTOS, 2005, p. 135-136)

Há também notas que se relacionam com a estrutura interna da obra. Tais orientações são responsáveis por transmitir ao professor uma ideia de unidade que se justifica.

Todos os problemas da presente lição, cujas soluções e raciocínios devem ser exigidos dos alunos, consoante os exemplos dados, pertencem à razão direta. [...] Os problemas da lição seguinte, cujas soluções e raciocínios devem ser também exigidos dos discípulos, pertencem à razão inversa. (MONÇÃO, 1928, p. 177)

Já demos a este ponto, nas lições $75^{\mathrm{a}}$ e $76^{\mathrm{a}}$, o necessário desenvolvimento; não obstante, para atendermos aos programas, damos aqui alguns novos problemas com os respectivos raciocínios. (MONÇÃO, 1928, p. 261)

Em especial, ao final das Partes de cada Livro, Monção indica em nota a quantidade de problemas e exercícios que foram propostos e orientações quanto à distribuição das lições considerando o tempo disponível, como, por exemplo, as notas da página 77:

Nota I - Nas 25 lições da Parte Primeira do Livro Primeiro contam-se 300 problemas e exercícios.

Nota II - Dividindo o professor o número de dias letivos de um semestre, pelo número de lições do mesmo, encontrará quantas vezes deve ensinar uma mesma lição. (MONÇÃO, 1928, p. 77)

De maneira geral, o sistema de notas de rodapé constituído por Monção é responsável pela validação do caráter erudito e confiável da obra.

Para a maioria dos leitores, as notas de rodapé exercem um papel diferente. Em uma sociedade moderna, impessoal, na qual os indivíduos precisam, para a maioria dos ofícios, confiar em outros dos quais nada sabem, as credenciais fazem o que a recomendação pessoal costuma fazer: elas dão legitimidade. (GRAFTON, 1998, p. 19)

22 VIÑAO FRAGO, A.; ESCOLANO BENITO, A. Currículo, espaço e subjetividade. A arquitetura como programa. Rio de Janeiro: DP\&A, 1998. 


\section{Considerações finais}

No Prólogo da segunda edição Monção considera que a sua aritmética foi um sucesso editorial, com a venda total do estoque de dois mil e quinhentos exemplares. E, neste prefácio, Monção ampliou suas finalidades quanto ao destinatário e considerou também o aluno como consumidor.

Publiquei a primeira edição deste nosso modesto trabalho, em meado de abril de 1923, tivemos, desde então, o prazer de vê-lo aceito pelo público em geral [...] A presente edição [segunda] foi moldada aos programas de ensino de vários Estados do Brasil, e por isso, contém, além de todos os pontos, sem exclusão de um só dos programas que baixaram com o Decreto n.6758, de 1 de janeiro de 1925, a "muitos outros ainda, pelo que a matéria nela estudada constituiu o "Curso primário e complementa".

Ampliada assim nossa obrinha, a "Arithmetica Elucidativa" será, no Brasil, destinada aos professores, aos alunos das escolas primárias e dos cursos complementares [...] e ainda, às alunas do curso normal [...] (MONÇÃO, 1928, p. 12).

As informações na folha de rosto da terceira edição indicam também que a obra era "destinada aos professores e alunos, às escolas normais e às de comercio, aos colégios, liceus e ginásios" e que havia sido ampliada, melhorada e acrescida de "muitas lições" para o curso secundário. (MONÇÃO, 1928). Ainda sobre a terceira edição, o Jornal do Brasil, de 24 de junho de 1928, noticia que as duas primeiras edições foram vendidas "em pouco mais de 2 anos", em um total de 7600 exemplares.

Mesmo com um caráter híbrido quanto ao público alvo, apontado por Monção ao longo das três primeiras edições, ainda assim é possível fazer uma leitura considerando este livro um manual para o professor ${ }^{23}$. Monção constituiu os diálogos e estruturou a obra de maneira que o contexto de sala de aula e a prática do professor se tornassem dependentes do uso do livro. As mediações entre "o aluno e os saberes e práticas" e entre "o aluno e o professor", dimensões do "contrato de leitura e utilização proposto pelo livro didático", são estabelecidas, neste caso, a partir de relações não autônomas entre impresso didático e professor. (BATISTA, 1999, p. 551-553).

A aritmética de Monção encontra-se, portanto, em sua origem, na contramão da produção editorial e suas relações com o destinatário, tornando-se assim mais um contraexemplo nesse contexto. Como relatado por Batista (1999), Bittencourt (1993) ${ }^{24}$ "mostra que o livro se destinava prioritariamente ao professor, devendo assegurar seu domínio dos conteúdos básicos a serem transmitidos aos alunos" garantindo assim a

\footnotetext{
${ }^{23}$ Uma releitura da obra pode ser feita considerando como consumidor o aluno. Para Garnica e Souza (2012), "É [...] importante reiterar que um documento não fala por si, mas responde às perguntas que lhe são feitas. Assim, um mesmo documento por dizer coisas diferentes a pesquisas diferentes, dependendo do que cada pesquisador deseja estudar" (GARNICA; SOUZA, 2012, p. 30-31).

24 BITTENCOURT, C.M.F. Livro didático e conhecimento histórico: Uma história do saber escolar. 1993. Tese (Doutorado em História Social). Faculdade de Filosofia, Letras e Ciências Humanas, Universidade de São Paulo, São Paulo, 1993.
} 
ideologia desejada. E ainda baseado em Bittencourt (1993), tem-se que "é só no decorrer do século XIX" que o livro passou a ser um bem consumido diretamente pelos alunos (BATISTA, 1999, p. 550). Por outro lado,

Mesmo que o aluno tenha se tornado, com o passar do tempo, o destinatário privilegiado do impresso didático, ainda no século $\mathrm{XX}$ podem ser encontrados livros destinados prioritariamente ou exclusivamente a docentes. Na década de 1930, por exemplo, um "amigo da instrução" (como costumavam se autodenominar muitos autores de livros didáticos que preferiam se manter no anonimato) publicou um livro [...] destinado a auxiliar o professor na exploração do vocabulário (sua compreensão e pronúncia adequada) dos textos de um outro livro didático - a "Antologia Nacional", de Fausto Barreto e Carlos de Laet (1913) [...] (BATISTA, 1999, p. 550-551)

Considera-se também importante destacar que a leitura de Monção potencializa “deslocamentos" (GALVÃO; BATISTA, 2008, p. 167) em relação a pesquisas sobre livros didáticos por se interessar por um livro pouco citado na historiografia. Além disso,

[...] acreditamos na necessidade de que sejam realizados estudos, por um lado, de caráter mais panorâmico, que subsidiem a formulação de pesquisas mais específicas. Por outro lado, é também necessária, para um melhor conhecimento do gênero, a realização de estudos monográficos, de modo a possibilitar a verticalização e o aprofundamento de certas questões pouco visíveis através da realização de estudos gerais, horizontais. (GALVÃO; BATISTA, 2008, p. 169).

A aritmética de Monção é um exemplo de diversidade e instabilidade que a produção didática possui e que acarreta dificuldade, como citado no início deste artigo, de apreensão e conceituação do livro didático no Brasil.

\section{Referências}

ALMEIDA, M.Z.C.M de. Educação e memória: velhos mestres de Minas Gerais (1924-1944). Brasília, 2009. Tese (Doutorado em História) - Departamento de História, Universidade de Brasília.

ARAÚJO, E. A construção do livro: princípios e técnicas de editoração. 2 ed. São Paulo: Editora da UNESP, 2008.

BARRA, V.M.L. da. A lousa de uso escolar: traços da história de uma tecnologia da escola moderna. Educar em Revista, Curitiba, Brasil, n. 49, p. 121-137, jul./set. 2013. Editora UFPR. Disponível em:< http://www.scielo.br/pdf/er/n49/a08n49.pdf.> . Acesso em 17 jan 2015. 
BASTOS, M.H.C. Do quadro-negro à lousa digital: a história de um dispositivo escolar. Cadernos de História da Educação, nº. 4, p. 133-141, jan./dez. 2005. Disponível em:< http://www.seer.ufu.br/index.php/che/article/view/391>. Acesso em 20 jan 2015.

BATISTA, A.A.G. Um objeto variável e instável: textos, impressos e livros didáticos. In: ABREU, M. (Org.). Leitura, história e história da leitura. Campinas, SP: Mercado das Letras, 1999. (Coleção Histórias de Leitura), pp. 529-575.

BITTENCOURT, C. Livro didático e saber escolar: 1810-1910. Belo Horizonte: Autêntica Editora, 2008. (História da Educação).

BRASIL. Diário Official da União. Seção I, 30 de outubro de 1928, p. 23474.

BRASIL. Edital de convocação para o processo de inscrição e avaliação de obras didáticas para o Programa Nacional do Livro Didático - PNLD 2015. Brasília: MEC/FNDE/SEB, 2013. Disponível em: <http://www.fnde.gov.br/arquivos/category/165-editais?download=8304: edital-pnld-2015-ensino-medio-03-07-2013>. Acesso em: 3 dez 2013.

BELTRAME, J. Os programas de ensino de matemática do Colégio Pedro II: 1837-1932. Rio de Janeiro, 2000. Dissertação (Mestrado em Matemática) - Departamento de Matemática, Pontifícia Universidade Católica do Rio de Janeiro.

COLLECÇÃO das Leis e Decretos do Estado de Minas Gerais - 1918. Bello Horizonte: Imprensa Official do Estado de Minas, 1918. Disponível em:< https://repositorio.ufsc.br/xmlui/handle/123456789/122286>. Acesso em 20 nov 2014.

COLLECÇÃO das Leis e Decretos do Estado de Minas Gerais - 1925. Bello Horizonte: Imprensa Official do Estado de Minas, 1926. Disponível em:< https://repositorio.ufsc.br/xmlui/handle/123456789/122339>. Acessso em 20 nov 2014.

COSTA, D.A. da. A aritmética escola no ensino primário brasileiro: 1890-1946. São Paulo, 2010. Tese (Doutorado em Educação Matemática), Pontifícia Universidade Católica de São Paulo.

DARNTON, R. O beijo de Lamourette: mídia, cultura e revolução. São Paulo: Companhia das Letras, 2010.

DASSIE, B.A.; BAPTISTA, W.L.B. Orientar para usar o livro didático e usar o livro didático para orientar: uma análise do "sistema de notas" de Jácomo Stávale. In GARNICA, A.V.M; SALANDIM, M.E.M. (Orgs.). Livros, leis, leituras e leitores: exercícios de interpretação para a história da educação matemática. Curitiba: Appris, 2014.

DORDAL, R.C. Arithmetica escolar: Livro do mestre - Guia pedagógico. Rio de Janeiro: Livraria Francisco Alves, 1915.

EULALIO, J. Postilas de mathematica: algebra, $1^{\mathrm{a}}$ e $2^{\mathrm{a}}$ parte. Rio de Janeiro: Imprensa Nacional, 1909a.

EULALIO, J. Postilas de mathematica: arithmetica, $2^{\text {a }}$ parte. Rio de Janeiro: Imprensa Nacional, 1909b. 
F.T.D. Soluções e respostas dos exercícios e problemas contidos no livro Elementos de Arithmetica. Rio de Janeiro: Livraria Paulo Azevedo \& C., s./d.

GALVÃO, A.M.O.; BATISTA, A.A.G. Manuais escolares e pesquisa em história. In: VEIGA, C.G.; FONSECA, T.N.L (org.) História e historiografia da educação no Brasil. Belo Horizonte: Autêntica, 2008, p. 161-188.

GARNICA, A.V.M.; SOUZA, L.A de. Elementos de história da educação matemática. São Paulo: Cultura Acadêmica, 2012.

GENETTE, G. Paratextos editoriais. Cotia, SP: Ateliê Editorial, 2009.

GÉRARD, F.M.; ROEGIERS, X. Conceber e avaliar manuais escolares. Porto: Porto Editora, 1998. (Colecção Ciências da Educação, 30).

GOMES, M.L.M. História da matemática e positivismo nos livros didáticos de Aarão Reis. Revista Brasileira de História da Educação, n 18, p. 69-94, set./dez. 2008.

GRAFTON, A. As origens trágicas da erudição: pequeno tratado sobre a nota de rodapé. Campinas: Papirus, 1998.

MONÇÃO, N.B. Arithmetica elucidativa. 3 ed. Rio de Janeiro: Autor, 1928.

PEREZ Y MARIN, A. Lições de álgebra. São Paulo: Escolas Profissionais do Lyceu Coração de Jesus, 1918.

PEREZ Y MARIN, A. Soluções arithmeticas. 2 ed. São Paulo: Escolas Profissionais do Lyceu Coração de Jesus, 1925.

PEREZ Y MARIN, A. Soluções algebricas. 2 ed. São Paulo: Escolas Profissionais do Lyceu Coração de Jesus, 1927.

SOARES, M. B. Um olhar sobre o livro didático. Presença Pedagógica. v.2, n. 12, p.53-63, nov./dez., 1996.

VALENTE, W. R. Uma história da matemática escolar no Brasil (1730 - 1930). 2 ed. São Paulo: Annablume: FAPESP, 1999. 